\title{
O Potencial do Birdwatching na Área de Proteção Ambiental do Delta do Parnaíba (Piauí, Brasil)
}

\section{The Birdwatching Potential in the Parnaíba Delta Environmental Protection Area (Piauí, Brazil)}

\author{
Francisco das Chagas Vieira Santos, Luciana Batista Lima, \\ Muryllo dos Santos Nascimento, Solano de Souza Braga, Anderson Guzzi
}

\begin{abstract}
RESUMO: Este artigo apresenta o birdwatching (observação de aves) como possibilidade para diversificar as atividades de ecoturismo desenvolvidas na Área de Preservação Ambiental (APA) do Delta do Parnaíba, localizado no estado do Piauí. O objetivo deste trabalho foi analisar o potencial da APA para a implementação dessa atividade como suplemento para a conservação ambiental e fonte de renda para populações locais. O registro das espécies em campo, assim como o levantamento da infraestrutura básica e turística local, apontou o potencial turístico da avifauna identificada que deve ser fortalecido. Desta forma, torna-se necessário a mobilização e motivação da população local para conhecer as aves que fazem parte da paisagem para que possam ser desenvolvidos produtos relacionados ao birdwatching, como artesanato ou guias impressos informativos sobre as aves locais. Acredita-se que a participação do poder público é imprescindível na promoção de um roteiro de observação de aves, bem como na manutenção das reservas naturais existentes.
\end{abstract}

PALAVRAS CHAVE: Ecoturismo; Delta do Parnaíba; Birdwatching.

ABSTRACT: This article presents birdwatching as a possibility to diversify the ecotourism activities developed in the Environmental Preservation Area (EPA) of the Parnaíba Delta, located in the state of Piauí. The objective of this work was to analyze the potential of the EPA for the implementation of this activity as a supplement for environmental conservation and source of income for local populations. The field record of the species, as well as the survey of basic infrastructure and local tourism, pointed out the tourist potential of the identified avifauna that should be strengthened. In this way, it becomes necessary the mobilization and motivation of the local population to know the birds that are part of the landscape so that products related to birdwatching can be developed, such as handicrafts or printed information guides on the local birds. It is believed that the participation of the public power is essential in the promotion of a route of birdwatching, as well as in the maintenance of existing natural reserves.

KEYWORDS: Ecotourism; Parnaíba Delta; Birdwatching. 


\section{Introdução}

O turismo com base na natureza, também conhecido como ecoturismo, é um dos segmentos que mais tem crescido em todo o mundo em virtude do interesse das populações em temas relacionados ao meio ambiente (DIAS, 2011; COELHO et al., 2008). O turismo em áreas naturais cresceu de tal forma que as atividades disponibilizadas aos turistas estão cada vez mais diversificadas. Desta forma, elas estão se tornando cada vez mais específicas e atualizadas, gerando aos turistas ávidos por conhecimento, novas visões de áreas naturais (DIAS; FIGUEIRA, 2010).

Nesse sentido, tem-se percebido a importância do ecoturismo na construção de uma sociedade baseada nos pilares da sustentabilidade (social, econômico e ambiental). Há diversos tipos de produtos turísticos que podem ser enquadrados como turismo com base na natureza, como aqueles que buscam a observação de animais na natureza, a vivência em ambientes naturais, apreciação de paisagens naturais, dentre outros. Esse tipo de turismo apresenta um vasto alcance, tais como: ecoturismo $^{1}$, turismo rural $^{2}$, de sol e praia $^{3}$, turismo esportivo ${ }^{4}$, náutico ${ }^{5}$ e turismo de aventura $^{6}$ (BRASIL, 2006)

O mercado primário do ecoturismo caracteriza-se por indivíduos oriundos, em particular, dos países considerados como maiores emissores de turismo (EUA, Canadá, Austrália, Alemanha e Reino Unido), conscientes da necessidade de preservar os escassos recursos ambientais existentes e que procuram, enquanto destino para as suas viagens, locais onde a intervenção humana seja reduzida no sentido de aproveitar a beleza paisagística natural (DIAS; FIGUEIRA, 2010).

Em sentido amplo, ecoturistas são pessoas com espírito de aventura, curiosas, investigativas. Gostam de compartilhar experiências e atividades que estabeleçam contato com a natureza, que lhes proporcionem prazer na observação da fauna em seu habitat. Buscam explorar e descobrir sobre costumes culturais das regiões que visitam. Possuem como característica o trabalho em equipe e o companheirismo e sentem-se recompensadas com o que podem identificar durante a exploração, como a beleza de um lugar inóspito, a visão de uma cachoeira, o voo de um tucano ou a vista de jacarés preguiçosos às margens de uma lagoa (LOPES; SANTOS, 2004).

Segundo Sinha (2001) o foco no turismo de vida selvagem é decorrente de três fatores, sendo o primeiro, um crescimento no interesse do gerenciamento desta "vida selvagem" por profissionais, governos e organizações não-governamentais em sinergia às atividades turísticas e de conservação. O segundo são os animais selvagens são cada vez mais utilizados pelo e para turismo, como estratégias de marketing em alguns países (por exemplo, Escócia: aves e mamíferos marinhos, Índia: tigres, China: pandas gigantes). Segundo o autor, este segundo fator está associado ao terceiro: para muitos turistas os animais selvagens são, particularmente, mais interessantes em relação aos outros elementos da natureza (BRUMATTI, 2013). A observação de aves é uma atividade que segue a vertente contemplativa do ecoturismo (MOHR, 2004).

Nesse contexto, a prática da observação da fauna é considerada a atividade mais sustentável entre todas as que são identificadas com o ecoturismo (DIAS, 2011). Um dos aspectos econômico-recreativos cada vez mais consensuais radica na observação das espécies nos seus habitats naturais, aliando os aspectos lúdicos dos passeios a uma vertente recreativa de cunho científico-cultural. Assim, temos a observação de aves, ou birdwatching, uma atividade que tem passado por forte 
impulso nestes últimos anos e que pode ser praticada tanto numa vertente recreativa como turística (AMARAL; FONSECA, 2010).

Considerado um nicho de mercado, o turismo ornitológico, constitui uma das atividades em acelerado crescimento, pois envolve de modo concreto o visitante com uma prática ecológica que antecede e se estende muito além da visitação, exigindo preparo, planejamento e posterior avaliação (DIAS, 2011). "O turismo de observação de aves tem grande potencial de retorno financeiro para as comunidades receptivas criando incentivos para proteção ambiental de áreas naturais" (COELHO et al., 2008, p.18). Por outro lado, este autor destaca que demanda esforço de marketing por parte dos destinos que apresentem em algum grau uma presença de espécies carismáticas ou uma diversidade significativa de muitas outras.

Dessa forma a atividade caracteriza-se como uma atividade de lazer baseada na observação das aves no seu meio natural, que pode ser feita de forma simples mais também com recurso de binóculos e telescópios de campo e oportuniza outras variantes como a fotografia, a pintura e a ilustração da natureza (DIAS; FIGUEIRA, 2010). De forma técnica, o autor também ressalta que é uma atividade que exige conhecimento especializado em ornitologia, levantamentos periódicos da população de aves, identificação das espécies e integração em diversas redes de acompanhamento de grupos específicos de aves, além da particularidade de recepção de turistas diferenciados, com alto nível de exigência de qualidade no atendimento de seus interesses, além de uma perfeita sincronização dos períodos de visitação nos locais que oferecem as melhores condições de visualização de espécimes.

Os Birdwatchers é o termo utilizado para caracterizar os observadores de aves, sendo designado pelo deslocamento de pessoas para fora da área de residência para observação de aves em habitat natural (ANDRADE, 1997). Tornaram-se o maior grupo de registro da vida silvestre do planeta e a comunidade de contemplação da natureza que mais cresce no mundo atualmente (COELHO et al., 2008).Os primeiros grupos de observadores de aves surgiram na Europa e posteriormente na América do Norte, sendo atualmente uma atividade bem difundida e praticada por uma boa parte da população destes dois continentes (YOUTH, 2000; FIGUEIREDO, 2007; CARVER, 2009; ALEXANDRINO, et al., 2012, p.29). Os observadores de aves tornaram-se o maior grupo de registro da vida silvestre do planeta e é a comunidade de contemplação da natureza que mais cresce no mundo. (COELHO et al., 2008: 18)

Por outro lado, apesar do Brasil apresentar grande riqueza em termos de biodiversidade nesse caso, com grande diversidade da avifauna brasileira (terceira maior do mundo) não se tem beneficiado de um aumento do fluxo de turistas internacionais (DIAS, 2011). A maioria dos brasileiros, incluindo as operadoras de ecoturismo, conhece muito pouco sobre as mais de cem mil espécies da fauna brasileira e, por essa razão, não sabe identificá-la e valorizá-la (OPLLIGER, et al., 2016). "O turismo de observação de aves planejado pode proporcionar um crescimento do ecoturismo [...], trazendo mais recursos financeiros, aumentando 0 desenvolvimento socioeconômico na região" [...]. (COELHO et al., 2008, p.18)

Os problemas que afetam esse tipo de turismo são, basicamente, os mesmos dos outros segmentos mais tradicionais: falta de infraestrutura, baixa capacitação da mão-de-obra, falta de sinalização, ausência de medidas de segurança, falta de 
investimentos e principalmente a falta de uma iniciativa que venha a promover esta atividade por meio da educação ambiental (DIAS, 2011; LOPES; SANTOS, 2004).

Assim, embora esse segmento do turismo ecológico, ainda não seja presente e intenso como uma oferta em redes de hotéis rurais e/ou ecológicos no Brasil, esta atividade já existe como hobby e lazer em algumas Unidades de Conservação. Coelho et al., (2008) ressalta que o birdwatching possui "grande potencial de retorno financeiro para as comunidades receptivas, melhorar a economia e meio ambiente local, educar comunidade para o valor da biodiversidade e criar incentivos para sucesso da proteção ambiental de áreas naturais" (SEKERCIOGLU, 2002; PIVATO, 2003; PIVATO; SABINO, 2005; COELHO et al., 2008, p.20).

Nesta perspectiva, a atividade de observação de aves possui um público restrito e seleto, formado geralmente por pessoas de meia idade. Caracterizam-se por viajarem normalmente em grupo e por possuírem elevados níveis de formação e empregos com rendimento acima da média e suas viagens duram em média 11 dias (AMARAL; FONSECA, 2010; LOPES; SANTOS, 2004). Estes visitantes gastam dinheiro em transportes, hotéis, restaurantes, guias locais, e souvenires; o que significa que enquanto os observadores de aves levam lembranças para os seus locais de origem, eles deixam para a localidade um conjunto recursos financeiros para os negócios locais (DIAS; FIGUEIRA, 2010).

Nessa direção, as localidades que possuem no seu território áreas propícias para observação de aves, tanto pelas suas características de biodiversidade ou pelo alto grau de endemismo, devem buscar transformar essa riqueza natural em recurso econômico através do ecoturismo de observação, no sentido de melhorar a qualidade e o nível de vida dos seus habitantes. E assim, ao compreender a importância da proteção dessas áreas, a população evitará a sua depredação por meio das inúmeras ameaças como queima, caça e turismo predatório (DIAS; FIGUEIRA, 2010). Outro aspecto bastante positivo são os vários ciclos biológicos e padrões de migração das aves, permitindo que o birdwatching não sofra de um dos problemas mais comuns que afeta o turismo nacional que é a sazonalidade (AMARAL; FONSECA, 2010).

Nessa perspectiva, o objetivo deste trabalho foi analisar o potencial da Área de Preservação Ambiental do Delta do Parnaíba, Piauí, para implementação da atividade de observação de aves, como suplemento ao ecoturismo na região, visando conservação ambiental e aumento de desenvolvimento econômico, por meio de incremento nas fontes de renda das populações locais.

\section{Material e métodos}

\section{Área de estudo}

A APA Delta do Parnaíba (Figura 1) foi criada pelo Decreto Federal de 28 de agosto de 1996, e envolve todo o litoral do estado Piauí e partes do Maranhão e Ceará, visando proteger os deltas dos rios Ubatuba, Timonha e Parnaíba; melhorar a qualidade de vida das populações residentes por meio da orientação e disciplina das atividades econômicas locais; Fomentar o turismo ecológico e a educação ambiental, além de preservar as culturas e as tradições locais (BRASIL, 1996). O clima, segundo a classificação de Koppen, é do tipo tropical quente e úmido (Aw), com alto índice de pluviosidade devido a influência da massa Equatorial Atlântica durante os meses de janeiro a junho (BASTOS, 2011). A região possui uma 
vegetação típica da restinga apresentando certa complexidade, sendo estruturada em três formações básicas: formação campestre, arbustiva e arbórea (SANTOSFILHO et al., 2010).

O Delta do Parnaíba localiza-se entre dois Parques Nacionais (PARNA), sendo eles 0 dos Lençóis Maranhenses, no Maranhão (MA), a oeste, no bioma Marinho Costeiro, com área de 156.608,16 hectares, e o PARNA de Jericoacoara, no estado do Ceará (CE), a leste, inserido no mesmo bioma, com área de 8.863,03 hectares. O Delta possui praticamente a totalidade do seu território inserido na APA do Delta do Parnaíba e na Reserva Extrativista (RESEX) Marinha do Delta do Parnaíba (ICMBio, 2018). Em todo o mundo existe somente duas formações congêneres, no rio Nilo, continente africano e no rio Mekong, continente asiático (MATTOS; IRVING, 2003, p. 24). Irving (2006, p. 24) destaca que:

[...] a região do Delta do Parnaíba, foi considerada uma área potencial a ser protegida. Em 1990, a região já havia sido considerada de interesse ecológico. Em 1997, foi criada a Área de Proteção Ambiental do Delta do Parnaíba e, no ano 2000, sobreposta a APA, foi criada a Reserva Extrativista Marinha do Delta do Parnaíba.

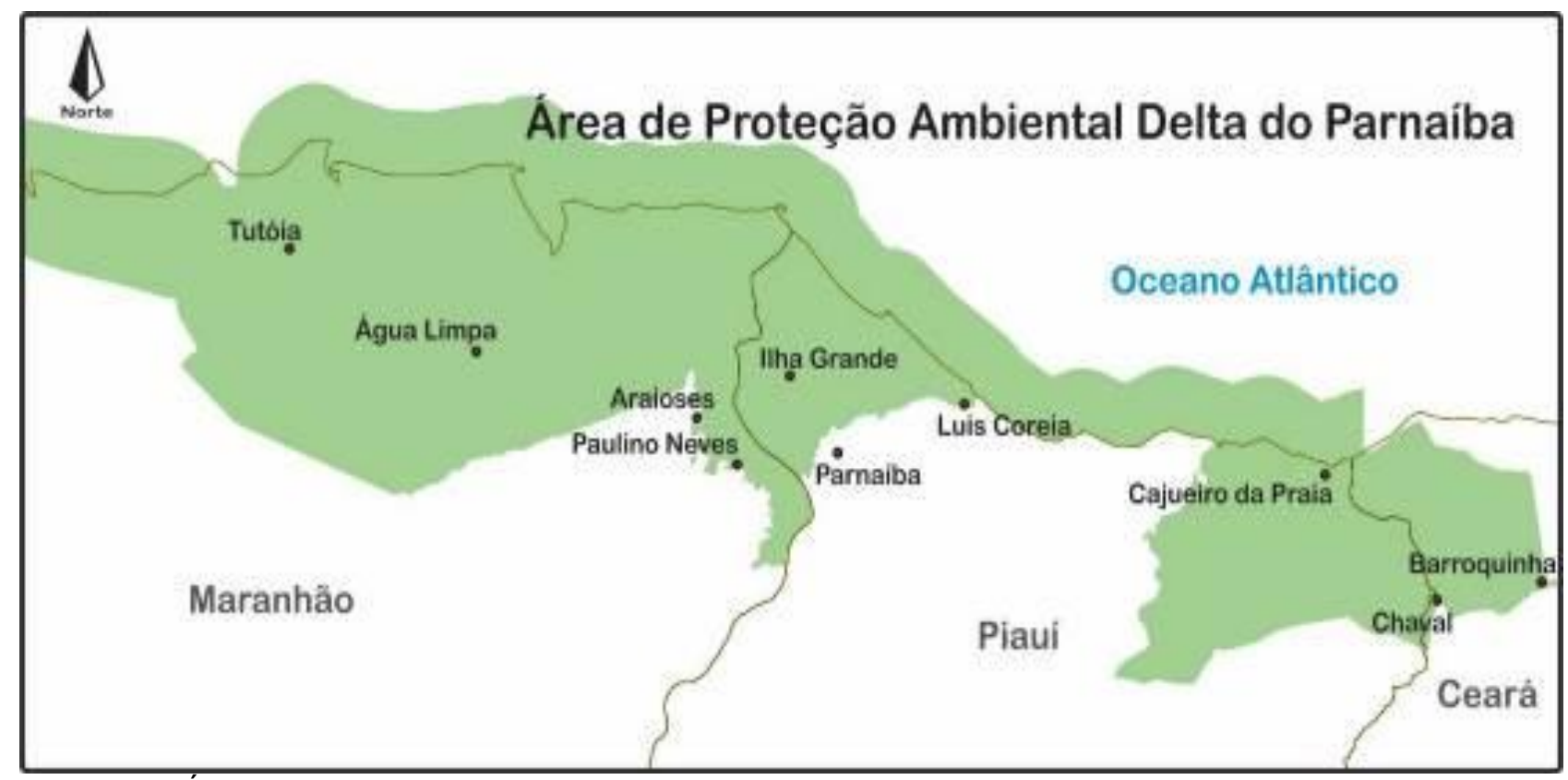

Figura 1: Área de Proteção ambiental Delta do Parnaíba - APA. Fonte: Base cartográfica ICMBio (2018).

Figure 1: Parnaíba Delta Environmental Protection Area - APA. Source: ICMBio cartographic base (2018).

\section{Avaliação do potencial para a observação de aves}

Buscou-se avaliar do potencial da atividade do Birdwatching na APA do Delta do Parnaíba através de dois importantes fatores: a riqueza e abundância das aves locais e a logística e infraestrutura específica que esta atividade requer. $O$ levantamento da avifauna da região deu-se através da compilação de documentos científicos (artigos em periódicos, monografias, dissertações, teses, livros e resumos 
em eventos científicos) disponíveis à consulta pública. Para isso, foi realizada uma revisão bibliográfica através do Portal de Periódicos da CAPES/CNPq, Scielo, Google acadêmico e bibliotecas virtuais das Instituições de Ensino Superior. Para a busca destes documentos foram utilizadas a combinação de algumas palavraschave como: aves, avifauna, Delta do Parnaíba, litoral do Piauí.

Em relação à logística e infraestrutura necessária para a inserção do Birdwatching na região, buscou-se conhecer as atividades turísticas já existentes na região e os recursos que são utilizados para tais atividade. Observou-se as rotas recomendadas aos turistas que visitam a APA e os meios como os turistas chegaram a estes destinos. Alguns aspectos específicos foram observados, como as trilhas feitas pelos visitantes e os guias que auxiliam nestas atividades.

\section{Resultados e discussão}

\section{Avifauna local e pontos de observação}

A partir da compilação das publicações referentes à avifauna presente na região do Delta do Parnaíba, pode-se observar uma diversidade favorável para atividades de Birdwatching (Figura 2).
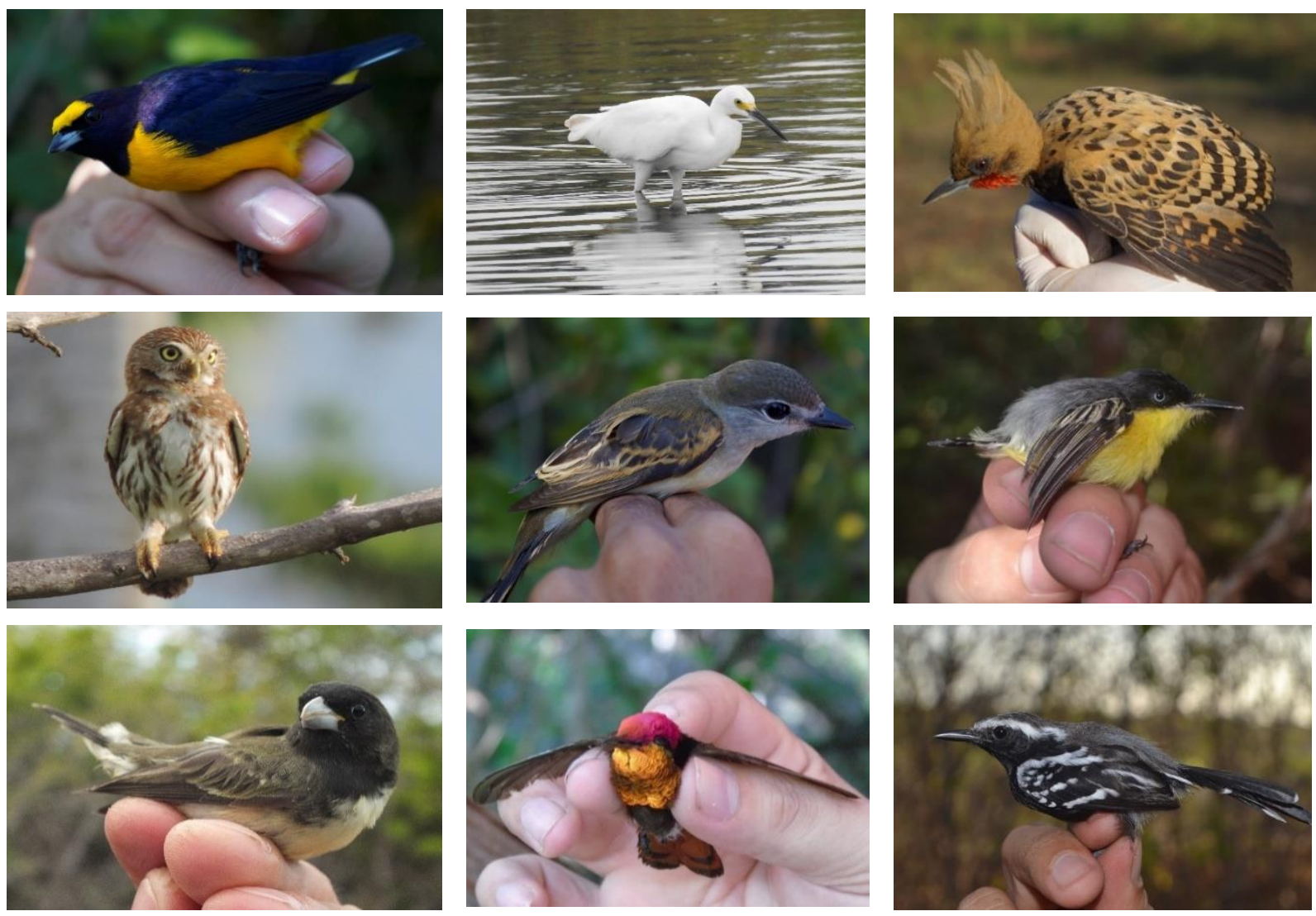

Figura 2: Algumas aves registradas na região da Área de Proteção ambiental Delta do Parnaíba.

Legenda. Da direita para a esquerda: Euphonia chlorotica; Egretta thula, Celeus ochraceus,

Glaucidium brasilianum, Pachyramphus polychopterus, Todirostrum cinereum, Sporophila nigricollis,

Chrysolampis mosquitus, Formicivora melanogaster. Fonte: Nascimento (2018).

Figure 2: Some birds registered in the Parnaíba Delta Environmental Protection Area region. Subtitle.

From right to left: Euphonia chlorotica; Egretta thula, Celeus ochraceus, Glaucidium brasilianum,

Pachyramphus polychopterus, Todirostrum cinereum, Sporophila nigricollis, Chrysolampis mosquitus, Formicivora melanogaster. Source: Nascimento (2018). 
Entre os estudos realizados na região, alguns merecem destaque: Santos (2011) levantou 12 espécies migratórias no complexo estuarino dos rios Cardoso/Camurupim no município de Cajueiro da Praia; Guzzi et al. (2012), em seis pontos dispostos na região do Delta do Parnaíba, registraram 139 espécies de aves das quais 113 foram consideradas residentes, 8 endêmicas do Brasil e 17 visitantes do Hemisfério Norte; Cardoso et al. (2013) registraram 82 espécies de aves distribuídas em 35 famílias, no Aeroporto Internacional de Parnaíba/PI, em área de restinga; Guzzi et al. (2015a) registraram 67 espécies de aves na praia da Pedra do Sal no litoral piauiense (16 migrantes neárticas e duas austrais); Guzzi et al. (2015b) registraram 161 espécies de aves na APA Delta do Parnaíba (três migrantes neárticas); Batista et al. (2016) inventariaram 2131 contatos com aves pertencentes a 36 espécies distribuídas em 19 Famílias e 13 Ordens. Mais recentemente Nascimento (2018), estudando os impactos de uma linha de transmissão na região da APA, registrou 224 espécies distribuídas em 25 ordens e 53 famílias.

Mediante às observações em campo e os locais de registro da avifauna obtidos através do levantamento bibliográfico, sugere-se pontos de observação onde os turistas poderão encontrar considerável número de espécies. Os pontos indicados podem ser acessados através de vias terrestres e aquáticas, mas atualmente não fazerem parte da programação dos roteiros turísticos da região, possuem considerável potencial ecoturístico (Figura 3).

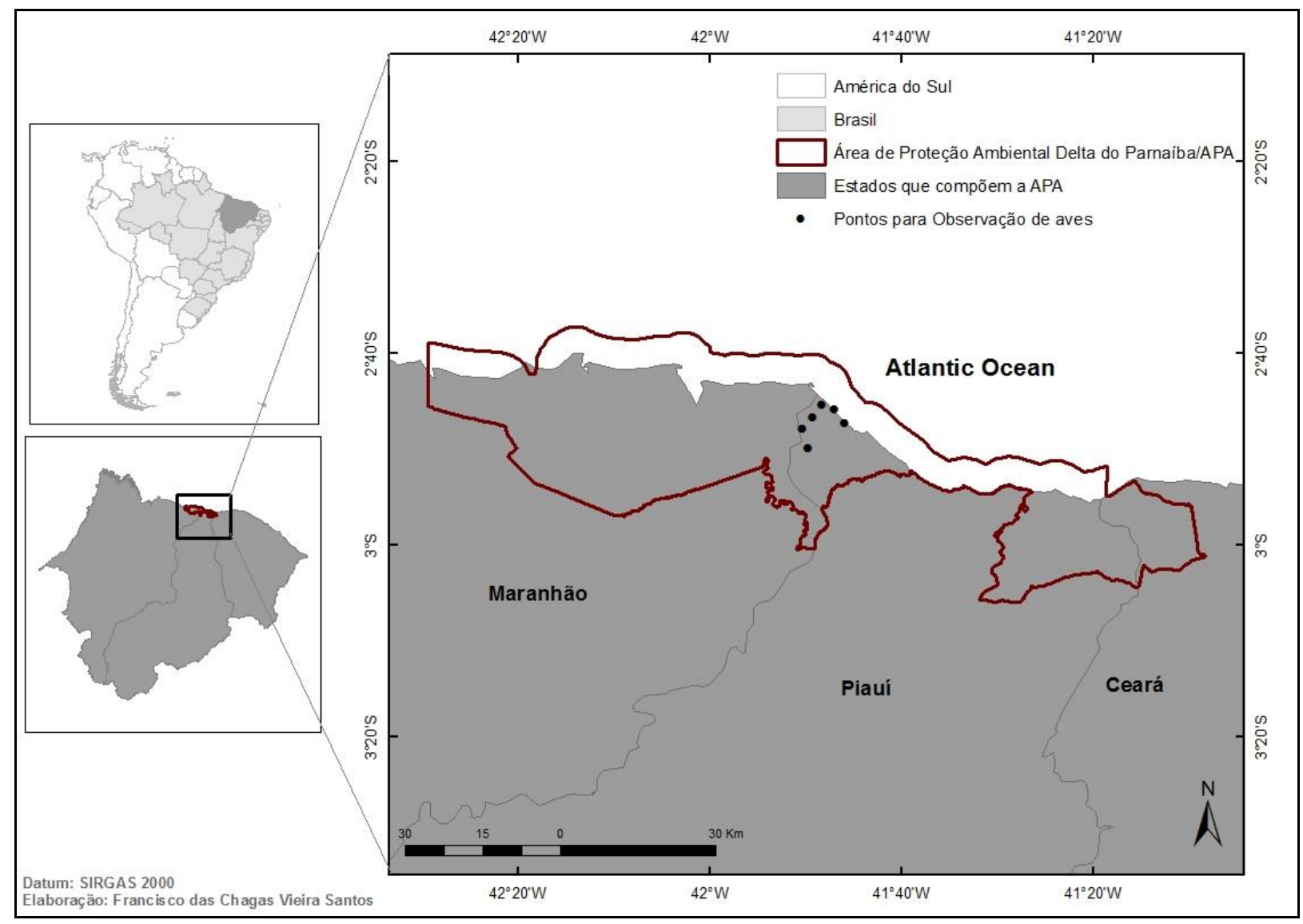

Figura 3: Pontos favoráveis para atividade de ecoturismo de Birdwatching na região do Delta do

Parnaíba que podem ser avistados durante o passeio de barco, Piauí, Nordeste, Brasil.

Figure 3: Favorable points for Birdwatching ecotourism activity in the Parnaíba Delta region that can be seen during the boat trip, Piauí, Northeast, Brazil.

Fonte da base cartográfica: Adaptado de IBGE (2010). Source of the cartographic base: Adapted from IBGE (2010). 


\section{Potencial para observação de aves}

Diante da observação na área de estudo, foi possível constatar que o turismo na região no APA do Delta do Parnaíba já é uma atividade bastante consolidada, fazendo parte do roteiro integrado de turismo Rota das Emoções, que se inicia no litoral cearense, especificamente na Praia de Jericoacoara, chega à região do Delta, e sugue rumo aos Lençóis Maranhenses. No município de Parnaíba, maior cidade da região norte do estado, é possível encontrar um significativo número de empresas turísticas que oferecem serviços turísticos que incluem passeios de barco ou lancha com destino às principais atrações da região que incluem praias, dunas, mangues e ilhas.

No tocante à observação de aves, a "revoada dos guarás" se consolida como uma das maiores atrações da região. Os turistas são instigados a acompanhar o momento em que os indivíduos desta espécie (Eudocimus ruber) retornam ao seu local de repouso, formando grandes bandos que se concentram na vegetação das ilhas presentes na região. Mediante suas características como bico fino, longo e plumagem de coloração vermelha muito forte (SICK, 1997) esta espécie chama bastante atenção das pessoas, no entanto, considerando a diversidade de aves presentes na região da APA do Delta do Parnaíba, é notório que a atividade de Birdwatching é pouco explorada. A presença de uma espécie símbolo para a região como o guará, fortalece o potencial para o turismo de observação de aves na APA. Esse é mais um aspecto que reforça o potencial da região, pois possibilita ações de marketing voltadas especificamente para esse segmento (DIAS, 2011).

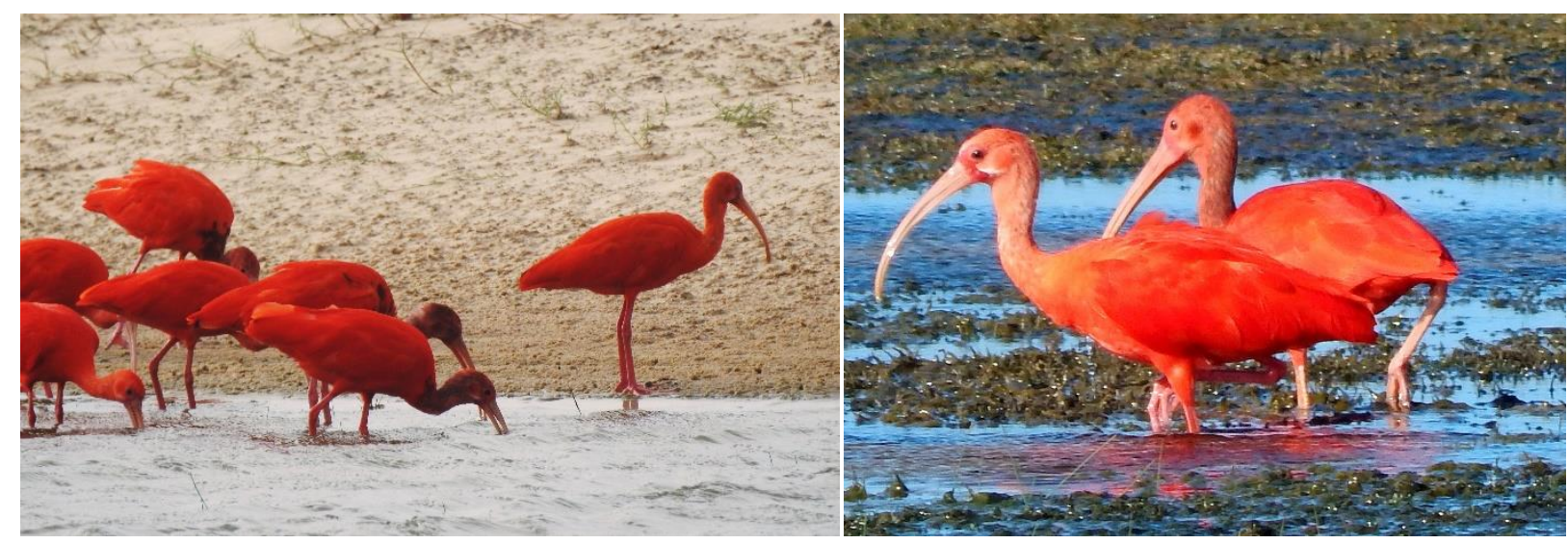

Figura 4: Eudocimus ruber, espécie abundante na região da APA do Delta do Parnaíba. Figure 4: Eudocimus ruber, species abundant in the Parnaíba Delta EPA region.

Fonte: Nascimento (2018).

Source: Nascimento (2018).

Tendo em vista a capacidade que a região tem para a observação de aves, algumas ações devem ser tomadas para a eficácia desta atividade. A região já possui uma boa infraestrutura para o turismo existente, porém, especificamente para a observação de aves é necessário a criação de bases de apoio, mirantes de observação, e lojas especializadas para venda e locação de produtos específicos para o Birdwatching como binóculos, guias, manuais e souvenir. Da mesma forma, apesar da existência de guias de turismo que informem os visitantes principalmente sobre a geografia local, é necessário a contratação de recursos humanos especializados na avifauna local, que conheçam as espécies, ondem elas podem ser encontras, e que possam passar essas informações de forma correta aos turistas. 
Dessa forma, Alexandrino et a.I (2012: 30) destaca que o "birdwatching, que se configura como uma opção de geração de renda local, se mostrando também como uma importante ferramenta de educação e conscientização ambiental" (SEKERCIOGLU, 2002; VIEIRA DA ROCHA; MOLIN, 2008).

Outra questão intimamente ligada ao ecoturismo e que poderia ser trabalha na região é a educação ambiental. Observou-se na área de estudo a quase inexistência de centros de educação ambiental. Trabalhar essa vertente, tanto com o turista, como com as comunidades locais, é de extrema importância para a conservação da biodiversidade. Segundo Machado Filho et al., (2008), a educação ambiental tem como um dos seus principais objetivos informar e sensibilizar as pessoas sobre as questões ambientais e torná-las atuantes na busca de soluções para os atuais problemas enfrentados. Diante disso, além de mostrar às pessoas as riquezas locais, como a diversidade de aves, é necessário mostrar a importância e apontar os perigos que o ser humano pode causar a esses recursos.

\section{Considerações finais}

Apesar da riqueza da avifauna na APA demonstrar-se estimulante para atividade de Birdwatching, o potencial turístico dessa atividade precisa ser fortalecido com outras ações, visto que o turismo na região é consolidado, com significativo número de empresas que oferecem serviços turísticos diversos. Observa-se ainda, que a "revoada dos guarás" é uma das maiores atrações da região, quando turistas são instigados a acompanhar o momento em que os indivíduos desta espécie retornam ao seu local de repouso.

Construir infraestrutura própria para as atividades de observação, como mirantes, bases de apoio ao observador de aves, centro de interpretação e educação ambiental, por exemplo, contribui para a apresentação de um produto turístico diferenciado e completo. Além disso, deve-se observar se oferta e demanda se complementam, se a infraestrutura básica é suficiente para atender à população local e aos visitantes; se existe infraestrutura específica adequada, além de se verificar se o produto oferecido atende às necessidades dos diferentes perfis de turistas.

Sugere-se que para aumentar a visitação pelos observadores de aves, a rede hoteleira da região estudada necessita investir em roteiros direcionados e também na divulgação da biodiversidade existente na região. Em sentido amplo, nesta pesquisa, constituiu-se num esforço em demonstrar a validade da atividade de observação de aves, associada à potencialidade dos recursos naturais do lugar, e principalmente o potencial da avifauna como atrativo, propondo-se que esta venha a ser desenvolvida como incremento ao ecoturismo local.

\section{Referências}

ALEXANDRINO, E.R.; QUEIROZ, O.T.M.M.; MASSARUTTO. R.C. O potencial do município de Piracicaba (SP) para o turismo de observação de aves (Birdwatching). Revista Brasileira de Ecoturismo, São Paulo, v.5, n.1, jan/abr-2012, pp.27-52.

AMARAL, S.; FONSECA, L. C. de. A avifauna como meio de valorização turística de uma zona da Ria Formosa - Faro. Actas do 6ํㅡㄹ Congresso a APDEA e IV Congresso de Gestão e Conservação da Natureza, Universidade dos Açores, Ponta Delgada, S. Miguel, Açores, 2010. 
ANDRADE, M.A. Aves silvestres: Minas Gerais. Belo Horizonte: Líttera Maciel. 1997. BASTOS, E.A. Boletim agrometeorológico de 2010 para o município de Parnaíba/Piauí. Teresina: Embrapa Meio-Norte, 2011. 32p

BATISTA, A.S.C. et al. Avifauna do carnaubal do Delta do Parnaíba, Piauí, Brasil. Gaia Scientia, v. 10, n. 4, p. 40-56, 2016.

BRASIL, Ministério do Turismo. Segmentação do Turismo: marcos conceituais. Brasília: Ministério do Turismo, 2006.

BRASIL. Decreto n $\mathbf{9 9 . 2 7 4}$, de 6 de junho de 1990. Dispõe sobre a criação da Área de Proteção Ambiental Delta do Parnaíba, nos Estados do Piauí, Maranhão, e Ceará. Diário Ofcial da República Federativa do Brasil, Poder Executivo. Brasília, 28 ago, 1996.

BRUMATTI, P.N.M. O papel do turismo de observação da vida selvagem para a conservação da natureza. Anais do IX Congresso Nacional de Ecoturismo e do V Encontro Interdisciplinar de Turismo em Unidades de Conservação. Revista Brasileira de Ecoturismo, São Paulo, v.6, n.4, nov-2013, pp.191-206.

CARDOSO, C.O. et al. Análise e composição da avifauna no Aeroporto Internacional de Parnaíba, Piauí. Ornithologia, v. 6, p. 89-101, 2013.

CARVER, E. Birding in the United States: A Demographic and Economic Analysis. Addendum to the 2006 National Survey of Fishing, Hunting, and WildlifeAssociated Recreation. Arlington, VA: U.S. Fish and Wildlife Service, Division of Economics. 2009. Disponível em: <library.fws.gov/pubs/birding natsurvey06.pdf>. Acessado em: 02 out 2018.

COELHO, A.G.; MACHADO, C.G.; CARVALHO, H.D.S.; NOLASCO, M.C. As aves das trilhas ecoturísticas de Igatu, Chapada Diamantina, Bahia. Revista Nordestina de Ecoturismo, Aracaju, v.1, n.1, p.18-33, 2008.

DIAS, R. A biodiversidade como atrativo turístico: o caso do turismo de observação de aves no município de Ubatuba (SP). Revista Brasileira de Ecoturismo, São Paulo, v.4, n.1, 2011, p.111-122.

DIAS, R.; FIGUEIRA, V. O turismo de observação de aves: um estudo de caso do município de Ubatuba/SP-Brasil. Revista de Estudos Politécnicos Polytechnical Studies Review. Vol VIII, nำ14, 2010, 085-096.

FIGUEIREDO, L.F. A observação de aves: Esporte, Lazer, Ciência e Arte. Centro de Estudos Ornitológicos. Disponível em: <http://www.ceo.org.br/>. Acessado em 04 ago 2011. 2007.

GUZZI, A. et al. Avifauna da APA (Área de Proteção Ambiental) Delta do Parnaíba/PI. In: MAGALHÃES, W. M. S.;NETO, M. O. M., et al (Ed.). Guia da Biodiversidade do Delta do Parnaíba. 1 Ed. Teresina-PI: EDUFPI, v.1, 2015b. p.13-65. ISBN 9788574639307.

GUZZI, A. et al. Composição e dinâmica da avifauna da usina eólica da praia da Pedra do Sal, Delta do Parnaíba, Piauí, Brasil. Iheringia, Série Zoologia v. 105, n. 2, p. 164-173, $2015 a$. 
GUZZI, A. et al. Diversidade de Aves do Delta do Parnaíba, Litoral Piauiense. In: GUZZI, A. (Ed.). Biodiversidade do Delta do Parnaíba, litoral piauiense. 1 ed. Teresina/PI: EDUFPI, v.1, 2012. p.291-327.

ICMBio. Instituto Chico Mendes de Conservação da Biodiversidade. Disponível em: Acessado em: <http://www.icmbio.gov.br/portal/> Out de 2018

IRVING, M. A. Reinventando a reflexão sobre turismo de base comunitária. In: BARTHOLO, R; BURSZTYN, I; SANSOLO, D. Turismo de Base Comunitária: diversidade de olhares e experiências brasileiras. Ed. Letra e Imagem, p. 108121, 2009.

LOPES, S.F.; SANTOS, R.J. Caminhos de Geografia. 5(13) 103-121, Out/2004.

MACHADO FILHO, H.O.; QUEIROZ, D.R.; GUERRA, R.A.T.; PEREIRA, M.G.; SIBRÃO, E.A.R. 2008. Educação Ambiental para um Futuro Melhor: Formação de uma Consciência Cidadã e Ambiental na Escola Pública. In: XI Encontro de Iniciação à Docência. Disponível em: <http://www.prac.ufpb.br/anais/xenex xienid/xi enid/ prolicen/ANAIS/Area5/5CCENDSEPLIC01.pdf>. Acesso em: nov. 2018.

MATTOS, F.F.; IRVING, M.A. Delta do Parnaíba nos rumos do ecoturismo: um olhar a partir da comunidade local. Caderno Virtual de Turismo, v. 3, n. 4, 2003.

MOHR, M. Observação de aves: uma oportunidade para o turismo rural. COAVE, 2004. Disponível em: <http://www.coeve.org.br>. Acesso em: nov.2018.

NASCIMENTO, M.S. Impactos ambientais da linha de transmissão Delta Tabuleiros sobre a avifauna, Piauí, Brasil. 2018. 92f. Dissertação (Mestrado em Desenvolvimento e Meio Ambiente) - Universidade Federal do Piauí, Teresina, 2018.

PIVATO, M.A.C. Turismo e observação de aves. In: SEMINÁRIO SUL-MATOGROSSENSE DE TURISMO DE NATUREZA, Campo Grande, 2003. Palestra. Disponível em: <http://www.atual.jc.nom.br>. Acesso em: nov 2018.

PIVATO, M.A.C.; SABINO, J. Recomendações para minimizar impactos à avifauna em atividades de turismo de observação de aves. Atualidades Ornitológicas, n.27, 2005.

SANTOS-FILHO, F.S. et al. Fisionomias das Restingas do Delta do Parnaíba, Nordeste, Brasil. Revista Brasileira de Geografia, v. 3, n. 3, p. 218-227, 2010.

SEKERCIOGLU, C.H. Impacts of birdiwatching on human and avian communities. Enviroumental Conservation, n.29, v.3, p.282-289, 2002.

SICK, H. 1997. Ornitologia brasileira. Rio de Janeiro, Editora Nova Fronteira, 912p.

SINHA, C. Wildlife tourism: a geographical perspective. Paper apresentado no The Geography Curriculum Inservice Conference, Tourism Geography: Issues, Challenges and the Changing Nature of Contemporary Tourism, University of Western Sydney, Hawkesbury Campus, 27 July 2001.

VIEIRA-DA-ROCHA, M.C.; MOLIN, T. A aceitação da observação de aves como ferramenta didática no ensino formal. Atualidades Ornitológicas, n.146, p. 33-37. 2008.

YOUTH, H. Watching vs. Taking. World Watch, v. 13, n.3, p. 12-23. 2000. 


\section{Notas:}

1 "Ecoturismo é um segmento da atividade turística que utiliza, de forma sustentável, o patrimônio natural e cultural, incentiva sua conservação e busca a formação de uma consciência ambientalista através da interpretação do ambiente, promovendo o bem-estar das populações." (MinTur, 2006, p. 9).

2 "Turismo Rural é o conjunto de atividades turísticas desenvolvidas no meio rural, comprometido com a produção agropecuária, agregando valor a produtos e serviços, resgatando e promovendo o patrimônio cultural e natural da comunidade." (MinTur, 2006, p. 49).

3 "Turismo de Sol e Praia constitui-se das atividades turísticas relacionadas à recreação, entretenimento ou descanso em praias, em função da presença conjunta de água, sol e calor." (MinTur, 2006, p. 43).

4 "Turismo de Esportes compreende as atividades turísticas decorrentes da prática, envolvimento ou observação de modalidades esportivas." (MinTur, 2006, p. 23).

5 "Turismo Náutico caracteriza-se pela utilização de embarcações náuticas como finalidade da movimentação turística". (MinTur, 2006, p. 23).

6 "Turismo de aventura compreende os movimentos turísticos decorrentes da prática de atividades de aventura de caráter recreativo e não competitivo" (Min Tur, 2006, p.39).

Francisco das Chagas Vieira Santos: Universidade Federal do Piauí, Parnaíba, PI, Brasil

E-mail: fcovieira2@hotmail.com

Link para o currículo Lattes: http://lattes.cnpq.br/8067628926151791

Luciana Batista Lima: Instituto Federal de Educação, Ciência e Tecnologia do Maranhão, São Luís, MA, Brasil

E-mail: luciana.lima@ifma.edu.br

Link para o currículo Lattes: http://lattes.cnpq.br/2094612735145586

Muryllo dos Santos Nascimento: Universidade Federal do Piauí, Parnaíba, PI, Brasil

E-mail: muryllobiologo@hotmail.com

Link para o currículo Lattes: http://lattes.cnpq.br/7288300254077205

Solano de Souza Braga: Universidade Federal do Piauí, Parnaíba, PI, Brasil

E-mail: solanobraga@yahoo.com.br

Link para o currículo Lattes: http://lattes.cnpq.br/3774316982731542

Anderson Guzzi: Universidade Federal do Piauí, Parnaíba, PI, Brasil

E-mail: guzzi@ufpi.edu.br

Link para o currículo Lattes: http://lattes.cnpq.br/1540345567927880

Data de submissão: 12 de fevereiro de 2019

Data de recebimento de correções: 31 de agosto de 2019

Data do aceite: 31 de agosto de 2019

Avaliado anonimamente 